\title{
Personality, personal values and cooperation preferences in public goods games: A longitudinal study
}

\author{
Stefan Volk ${ }^{\mathrm{a}, *}$, Christian Thöni ${ }^{\mathrm{b}}$, Winfried Ruigrok $^{\mathrm{c}}$ \\ ${ }^{a}$ University of Tübingen, Faculty of Business Administration and Economics, Melanchthonstr. 30, 72074 Tübingen, Germany \\ ${ }^{\mathrm{b}}$ University of St. Gallen, Department of Economics, Varnbüelstrasse 14, 9000 St. Gallen, Switzerland \\ ${ }^{\text {c } U n i v e r s i t y ~ o f ~ S t . ~ G a l l e n, ~ D e p a r t m e n t ~ o f ~ M a n a g e m e n t, ~ D u f o u r s t r a s s e ~ 40 a, ~} 9000$ St. Gallen, Switzerland
}

\section{A R T I C L E I N F O}

\section{Article history:}

Received 1 September 2010

Received in revised form 7 January 2011

Accepted 8 January 2011

Available online 2 February 2011

\section{Keywords:}

Personality

Big-five

Agreeableness

Values

Public goods game

Cooperation preferences

Experimental economics

Economic psychology

\begin{abstract}
A B S T R A C T
Recent research on behavioral heterogeneity in social dilemma situations has increasingly focused on exploring the predictive value of individual difference variables. This paper contributes to this line of research by examining how cooperation preferences in a series of three public goods games conducted over the course of five months are related to personality traits and personal values. A variant of the four player one-shot public goods game was administered to classify participants' cooperation preferences, along with measures of the Big-Five personality dimensions and Rokeach's terminal values. Results revealed that, when considered independently, Agreeableness and prosocial values were indicative of individual preferences for cooperation. However, when considered simultaneously, only Agreeableness emerged as a significant predictor of cooperation preferences. The findings are interpreted in terms of how personality and personal values jointly impact economic behavior.
\end{abstract}

(c) 2011 Elsevier Ltd. All rights reserved.

\section{Introduction}

The public goods game (PGG) and the prisoner's dilemma game (PDG) represent social dilemma situations in which a group or team of subjects is interdependent for obtaining outcomes. Subjects can achieve the highest possible outcome for the collective by cooperating, but each individual has an incentive to free ride on the cooperation of the others. A number of recent studies have examined the effects of individual difference variables on contribution decisions in PGGs (e.g., Fleming \& Zizzo, in press) and cooperative choices in PDGs (e.g., Hirsh \& Peterson, 2009).

Our research takes this analysis one step further by assessing the relationship between individual difference variables and cooperation preferences that form the basis of individual choices in PGGs and PDGs. We use a variant of the PGG developed by Fischbacher, Gächter, and Fehr (2001) in which participants, instead of making one contribution, submit a contribution schedule as a function of others' contributions. Unlike a single contribution decision, this schedule is a direct measure of individual cooperation preferences, allowing the classification of participants as either free riders or cooperators.

\footnotetext{
* Corresponding author. Tel.: +49 707129 78179; fax: +49 7071295534 .

E-mail addresses: stefan.volk@uni-tuebingen.de (S. Volk), christian.thoeni@ unisg.ch (C. Thöni), winfried.ruigrok@unisg.ch (W. Ruigrok).
}

In the present longitudinal study, we examine how cooperation preferences in a series of three PGGs conducted over the course of five months are related to the constructs of personality and personal values. Specifically, we investigate whether the Big-Five personality dimensions and Rokeach's (1973) terminal values are indicative of individual preferences for either cooperation or free riding. The Big-Five model is the standard trait framework for research in personality and specifies that five overarching dimensions (Extraversion, Agreeableness, Conscientiousness, Emotional Stability and Openness to Experience) account for the biggest part of between-subject variation in stable personality traits. Rokeach's value survey is a measure of the importance of two lists of terminal (end-states of existence) and instrumental (modes of conduct) values within a person's total belief system. We focus on the set of terminal values, because they are considered more fundamental than instrumental values, which are thought merely to refer to preferred modes of conduct that help achieve the desired end states of existence (Rokeach, 1973).

Olver and Mooradian (2003) and Parks and Guay (2009) provided excellent discussions of the relationship between personality and values. According to these authors, personality traits can be described as innate characteristics representing the nature of an individual, while personal values are socially learned beliefs about acceptable behavior and actions resulting from the interaction of nature and nurture. Parks and Guay (2009, p. 675) pointed out that 
"both are expected to influence a variety of behavioral outcomes, and so it seems evident that we should consider both in examining the impact of individual differences on behavior. Yet this practice is so infrequent, there is little understanding of how personality and values are related to one another, much less how they might jointly impact behavior".

The present paper contributes to this line of research by exploring how personality traits and personal values are separately and jointly related to individual preferences for cooperation in social dilemma situations.

\section{Methods}

The study was conducted three times over the course of five months and involved 72 students majoring in business administration. Four of these did not return for the third study leaving us with 68 participants with complete information at all three times (mean age 25.6, $\mathrm{SD}=3.2,49$ male). At time 1, students completed Gosling, Rentfrow and Swann's (2003) Ten-Item Personality Inventory (TIPI) and Rokeach's (1973) terminal value survey. Students also participated in a PGG, which was repeated after 2.5 months (time 2 ) and again after 5 months (time 3 ).

\subsection{Ten-Item Personality Inventory (TIPI)}

The TIPI includes two items for each of the Big-Five personality dimensions. Each item contains a pair of two trait descriptors and participants have to rate on a 7-point scale ranging from 1:'disagree strongly' up to 7:'agree strongly' the extent to which the pair of traits applies to them (see Gosling et al., 2003). We chose to adopt the TIPI rather than a longer personality measure to reduce transient measurement errors resulting from participant fatigue, frustration and boredom associated with completing several survey instruments in combination with a lengthy experimental session.

As a measure of the Big-Five dimensions of personality, the TIPI has been validated against standard Big-Five instruments. Gosling et al. (2003), for example, showed high convergent validity and discriminant validity of the TIPI with Costa and McCrae's (1992) 240-item NEO-PI-R. Furnham (2008) evaluated the TIPI relative to Costa and McCrae's (1992) 60-item NEO-FFI and found generally positive results in terms of validity. In a similar vein, Donnellan, Oswald, Baird, and Lucas (2006) and Ehrhart et al. (2009) demonstrated convergent validity of the TIPI with a number of longer five-factor model measures, including Goldberg's (1999) 50-item IPIP. All these extensive validation studies have shown that the TIPI has acceptable psychometric properties.

The Cronbach's alphas for the five TIPI scales in our study were very similar to the findings by Donnellan et al. (2006), Ehrhart et al. (2009) and Gosling et al. (2003), i.e.: Extraversion ( $\alpha=0.73$ ), Agreeableness $(\alpha=0.32$ ), Conscientiousness $(\alpha=0.49$ ), Emotional Stability $(\alpha=0.53)$ and Openness $(\alpha=0.46)$. With only two items per dimension, the relatively low alphas are to be expected as the computation of Cronbach's alpha is a function of the number of scale items. Test-retest reliability is therefore a more appropriate reliability measure for such brief scales. Gosling et al. (2003) reported test-retest reliability for the five TIPI scales over a period of six weeks. They were 0.77 for Extraversion, 0.71 for Agreeableness, 0.76 for Conscientiousness, 0.70 for Emotional Stability and 0.62 for Openness, indicating that the scale provides a stable measure of personality over time.

\subsection{Rokeach's terminal value survey}

Value priorities were assessed with Rokeach's terminal value list (see second column of Table 1) using a rating scale adopted
Table 1

Value domains from principal components factor analysis*.

\begin{tabular}{|c|c|}
\hline $\begin{array}{l}\text { Value domains for terminal } \\
\text { values }\end{array}$ & $\begin{array}{l}\text { Marker values in order of the level of the } \\
\text { factor loadings }\end{array}$ \\
\hline $\begin{array}{l}\text { Prosocial }(\alpha=0.78, M=5.60 \\
\qquad S D=0.87)\end{array}$ & $\begin{array}{l}\text { A World at Peace (free of war and conflict) } \\
\text { Inner Harmony (freedom from inner } \\
\text { conflict) } \\
\text { A World of Beauty (beauty of nature and the } \\
\text { arts) } \\
\text { Equality (brotherhood and equal } \\
\text { opportunity for all) } \\
\text { National Security (protection from attack) } \\
\text { Happiness (contentedness) } \\
\text { Freedom (independence and free choice) } \\
\text { Salvation (saved, eternal life) }\end{array}$ \\
\hline $\begin{array}{l}\text { Maturity }(\alpha=0.71, M=6.15 \\
\qquad S D=0.72)\end{array}$ & $\begin{array}{l}\text { Wisdom (a mature understanding of life) } \\
\text { Self-Respect (self-esteem) } \\
\text { True Friendship (close companionship) } \\
\text { An Exciting Life (a stimulating, active life) } \\
\text { Social Recognition (respect and admiration) }\end{array}$ \\
\hline $\begin{array}{l}\text { Enjoyment }(\alpha=0.67, M=6.01, \\
\quad S D=0.71)\end{array}$ & $\begin{array}{l}\text { Mature Love (sexual and spiritual intimacy) } \\
\text { A Comfortable Life (a prosperous life) } \\
\text { Pleasure (an enjoyable, leisurely life) } \\
\text { A Sense of Accomplishment (a lasting } \\
\text { contribution) } \\
\text { Family Security (taking care of loved ones) }\end{array}$ \\
\hline
\end{tabular}

${ }^{*}$ The table shows value domains obtained from principal components factor analysis with promax rotation. Cronbach's alphas $(\alpha)$, mean scores $(M)$ and standard deviations $(S D)$ in parentheses.

from Feather (1991). Participants rated the importance of each of the 18 terminal values on a scale ranging from 1 (not at all important to me) to 7 (extremely important to me). A rating response format was adopted because it allows for a more detailed analysis of value priorities than the traditional ranking method.

The intercorrelations between ratings for the 18 terminal values were factor analyzed using principal components analysis with promax rotation. Preliminary tests confirmed the suitability of our sample for factor analysis. Three factor extraction methods, Scree Test, Parallel Analysis and Velicer's MAP test all suggested a three-factor solution that explained $49 \%$ of the variance. Three subscales were constructed based on the values that had loadings greater than 0.40 on the relevant factor. The first subscale is largely consistent with the "Universal prosocial" domain specified by Feather (1991). While the majority of Rokeach's terminal values serve individualistic interests, most of the values included in this domain serve collectivistic interests and reflect therefore Schwartz and Bilsky's (1990, p. 879) definition of prosocial values, i.e. "Active protection or enhancement of the welfare of others." The second subscale mirrors Feather's (1991) "Mature accomplishment" domain and is related to Schwartz and Bilsky's (1990, p. 880), definition of maturity values, i.e. "Appreciation, understanding, and acceptance of oneself, others, and the surrounding world." The third subscale includes values related to Feather's (1991) "Comfort/Stimulation" and "Positive affiliation" domains and corresponds to Schwartz and Bilsky's (1990, p. 879), definition of enjoyment values, i.e. "Pleasure, sensuous and emotional gratification." Each participant's mean score on each subscale was taken as his or her score on the respective value domain. Table 1 summarizes the three value domains.

\subsection{Public goods game (PGG)}

Participants' cooperation preferences were assessed by a variant of the PGG developed by Fischbacher et al. (2001). In order to maximize comparability with the original experiment by Fischbacher et al. (2001), we replicated the same protocol and used the same parameters. 
We conducted the experiment with the same participant pool three times with 2.5 months in-between each repetition to allow for a more reliable assessment of participants' cooperation preferences and a more accurate classification into different cooperation types. The three sessions used an identical protocol in which participants were randomly assigned into groups of four. Group compositions were unknown to the participants and not revealed after the sessions.

The basic decision situation was a standard linear PGG. Each participant received an endowment of 20 tokens (worth $\$ 0.40$ each), any integer portion of which they could either keep privately or contribute to a group account. Contributions to the group account benefited all group members alike, that is, regardless of the amount contributed every group member received 0.4 times the sum of all contributions. Since participants earned exactly one token for each token they kept privately but only 0.4 token for each token they contributed to the group account, it was always in the participants' material self-interest to keep all tokens privately. However, if all four group members kept their whole endowment of 20 tokens privately, each participant earned only 20 tokens. On the other hand, if all four group members invested their whole endowment, each participant earned $0.4 \times 80=32$ tokens. The basic decision situation therefore confronted the participants with a classic social dilemma situation: the highest possible outcome for the group can be achieved by cooperating, but each individual group member benefits most from not cooperating.

In our PGG participants had to make two types of contribution decisions: an 'unconditional contribution' and filling in a 'contribution table'. The unconditional contribution was a single decision about how many of the 20 tokens to either keep privately or contribute to the group account. While this single contribution decision is often used as a measure of cooperative behavior, one cannot distinguish between different contribution preferences by only observing participants' unconditional contributions. For example, one cannot distinguish between participants who contribute nothing to the group account because they are self-interested and participants who would like to reciprocate others' cooperation, but contribute nothing because they believe pessimistically that others will not contribute. Previous research has shown that many individuals are conditional cooperators who condition their cooperation on the behavior of others by behaving cooperatively in response to cooperation but non-cooperatively in response to free riding (e.g., Fischbacher et al., 2001; Herrmann \& Thöni, 2009; Kelley \& Stahelski, 1970; Kramer, McClintock, \& Messick, 1986).

In order to be able to distinguish between different contribution preferences we asked participants to also indicate their contribution to the group account conditional on the average contribution of the other three group members. Specifically, participants had to fill in a contribution table showing in ascending order the 21 $(0-20)$ possible average contribution levels of the other three group members (rounded to integers). For each of these 21 possibilities participants had to indicate their corresponding contribution. The contribution table therefore elicited from each participant a contribution schedule as a function of others' contributions. This allowed us to classify our participants according to their cooperation preferences and distinguish, for example, between free riders and pessimistic conditional cooperators.

After all participants had made both types of decisions, i.e. the unconditional contribution and filling in the contribution table, a throw of a four-sided die randomly selected in each of the four-subject groups one subject. The three group members who were not selected contributed according to their unconditional contribution. The selected subject contributed according to his or her contribution table, based on the unselected subjects' average unconditional contributions. The purpose of this random mechanism was to make the decisions of both stages of the game potentially outcome relevant, giving participants an incentive to take both decisions seriously.

The experiments were conducted computerized in a lab using the software z-Tree (Fischbacher, 2007). The participants were randomly seated at computer terminals, which were separated by cardboard partitions to ensure that decisions were made in complete anonymity from the other participants. Communication between participants was strictly prohibited and neither before nor after the experiment could participants identify the other members in their group. They received written instructions explaining the experimental task in great detail. After reading the instructions, participants had to answer a number of control questions to prove their understanding of the task. The experiments did not proceed until all participants had answered all control questions correctly to ensure that everyone understood the mechanics and implications of the experimental task. At the end of the experiments participants were paid their experimental earnings privately to maintain their anonymity. They earned on average about US\$13 in each of the three experiments.

\section{Results}

\subsection{Cooperation types}

In our analysis we first categorized our participants according to their cooperation preferences in the PGG, measured by the contribution table described above. Following the procedure proposed by Fischbacher et al. (2001), we classified our participants in a first step into three categories.

Participants who reciprocated others' cooperation by submitting a contribution schedule that showed either a monotonically increasing pattern or had a significant positive slope $(p<0.01$, Spearman rank correlation) were classified as Conditional cooperators. Participants who had only ' 0 ' entries in their contribution schedule (i.e., contributed nothing in any case) were classified as Free riders. Fischbacher et al. (2001) also reported a so-called "hump-shaped" category of subjects who increased their contributions in the contribution schedule up to some maximum and decreased it thereafter. In our study we observed only very few hump-shaped contributors and therefore included them along with all unclassifiable participants into the category "Other". This category also contained a few unconditional cooperators who chose a constant non-minimal contribution in all cases.

Given that our subjects participated in a series of three PGGs conducted over the course of five months, we were able to refine Fischbacher et al.'s (2001) classification in a second step by also accounting for stability of cooperation preferences over time. Types were fairly stable over time with a Cramér's $V$ of $0.402(0.498)$ between measurement 1 and 2 (2 and 3 ). We distinguished between five cooperation types: A participant who was consistently classified as Conditional cooperator (Free rider) at all three times of measurement was categorized as ConsistentCC (ConsistentFR). Participants who were classified as Conditional cooperator (Free rider) in two out of three times were categorized as 2timesCC (2timesFR). The remaining participants were categorized as All Other. No subject showed a consistent hump-shaped or unconditional cooperation schedule.

\subsection{Big-Five personality dimensions and cooperation preferences}

Table 2 reports mean scores and standard deviations for the Big-Five personality dimensions separately for the five cooperation types.

A one-way analysis of variance showed that the average scores of the five cooperation types were not significantly different from 
Table 2

Descriptive statistics for Big-Five personality dimensions*.

\begin{tabular}{llllll}
\hline $\begin{array}{l}\text { Big-Five } \\
\text { personality } \\
\text { dimensions }\end{array}$ & $\begin{array}{l}\text { ConsistentCC 2timeCC 2timesFR ConsistentFR All } \\
(N=24)\end{array}$ & $(N=16)$ & $(N=5)$ & $(N=7)$ & $\begin{array}{l}\text { Other } \\
(N=16)\end{array}$ \\
\hline Extraversion & 4.81 & 5.38 & 4.60 & 3.43 & 4.53 \\
& $(1.77)$ & $(1.34)$ & $(0.42)$ & $(2.05)$ & $(2.08)$ \\
Agreeableness & 5.67 & 5.63 & 4.30 & 3.79 & 5.47 \\
& $(1.06)$ & $(0.92)$ & $(0.67)$ & $(0.95)$ & $(1.37)$ \\
Conscientiousness & 5.81 & 5.25 & 5.20 & 5.64 & 5.78 \\
& $(1.13)$ & $(1.47)$ & $(0.98)$ & $(0.85)$ & $(1.17)$ \\
Emotional Stability & 5.10 & 4.72 & 4.70 & 4.43 & 4.69 \\
& $(1.36)$ & $(1.53)$ & $(1.79)$ & $(1.97)$ & $(1.11)$ \\
Openness to Experience & 5.77 & 5.91 & 6.50 & 5.86 & 5.88 \\
& $(0.88)$ & $(0.94)$ & $(0.35)$ & $(1.41)$ & $(0.99)$ \\
\hline
\end{tabular}

The table shows mean scores for the Big-Five personality dimensions separately for the five cooperation types. Standard deviations in parentheses.

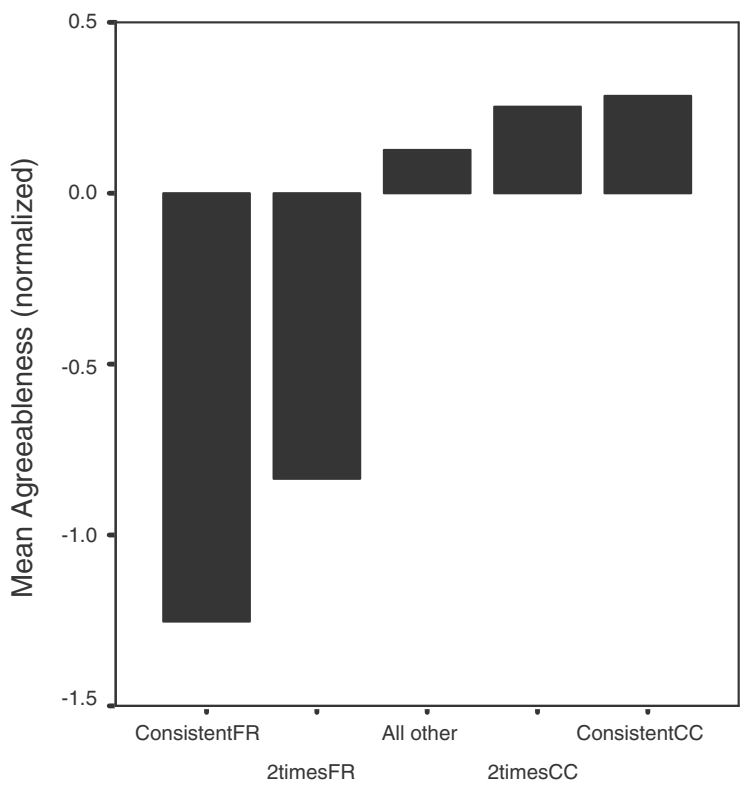

Fig. 1. The figure shows Agreeableness scores for the five cooperation types. To facilitate the interpretation we de-meaned and standardized the values of Agreeableness.

each other for Extraversion $(F=1.61, p=0.18)$, Conscientiousness $(F=0.76, p=0.56)$, Emotional Stability $(F=0.42, p=0.79)$ and Openness to Experience $(F=0.60, p=0.66)$. Significant effects were only observed for Agreeableness $(F=5.62, p<0.01)$. Follow-up $t$-tests revealed a positive relationship between participants' Agreeableness scores and their cooperation preferences in the PGG. Both ConsistentCC and 2timesCC scored significantly higher on Agreeableness $(p<0.01)$ than ConsistentFR and 2timesFR, with participants categorized as All other scoring in-between. Fig. 1 illustrates this relationship graphically.

In a more rigorous test of this relationship we ran a multinomial logistic regression (MLR) with Agreeableness scores as independent variable predicting cooperation type. Table 3 reports the results of our MLR analysis.

Parameters from Table 3 are best interpreted in terms of odds ratios $(\operatorname{Exp}(\lambda))$. For example, an increase of the Agreeableness score by one point made it 5.66 times more likely that a participant was categorized as ConsistentCC instead of ConsistentFR. The MLR-model reported in Table 3 had a Nagelkerke $R^{2}$ (variance explained) of 0.27 (Model Fit $\chi^{2}=19.71, p<0.01$ ).
Table 3

Multinomial logistic regression analysis*

\begin{tabular}{llrllll}
\hline $\begin{array}{l}\text { Dependent } \\
\text { variable: } \\
\text { Cooperation } \\
\text { type }\end{array}$ & $\begin{array}{l}\text { Independent } \\
\text { variable: }\end{array}$ & $\lambda$ & $\begin{array}{l}\text { Std. } \\
\text { error }\end{array}$ & Wald & $p_{\text {wald }}$ & $\operatorname{Exp}(\lambda)$ \\
\hline ConsistentCC & Intercepteness & & & & & \\
& Agreeableness & 1.73 & 0.58 & 8.89 & 0.003 & 5.66 \\
2timesCC & Intercept & -7.10 & 2.68 & 7.04 & 0.008 & \\
& Agreeableness & 1.69 & 0.60 & 8.11 & 0.004 & 5.44 \\
All Other & Intercept & -6.33 & 2.60 & 5.91 & 0.015 & \\
& Agreeableness & 1.55 & 0.59 & 7.04 & 0.008 & 4.74 \\
2timesFR & Intercept & -2.39 & 2.55 & 0.88 & 0.348 & \\
& Agreeableness & 0.51 & 0.61 & 0.70 & 0.402 & 1.66 \\
\hline
\end{tabular}

* The table shows parameter estimates $(\lambda)$ and odds ratios $(\operatorname{Exp}(\lambda))$ from MLR for four cooperation types. Reference category is ConsistentFR.

Table 4

Descriptive statistics for value domains*

\begin{tabular}{llllll}
\hline $\begin{array}{l}\text { Value } \\
\text { domains }\end{array}$ & $\begin{array}{l}\text { ConsistentCC } \\
(N=24)\end{array}$ & $\begin{array}{l}\text { 2timesCC } \\
(N=16)\end{array}$ & $\begin{array}{l}\text { 2timesFR } \\
(N=5)\end{array}$ & $\begin{array}{l}\text { ConsistentFR } \\
(N=7)\end{array}$ & $\begin{array}{l}\text { All Other } \\
(N=16)\end{array}$ \\
\hline Prosocial & 5.82 & 5.60 & 5.45 & 4.64 & 5.73 \\
& $(0.73)$ & $(0.85)$ & $(0.48)$ & $(1.21)$ & $(0.79)$ \\
Maturity & 6.24 & 6.06 & 6.32 & 5.77 & 6.21 \\
& $(0.70)$ & $(0.93)$ & $(0.46)$ & $(0.73)$ & $(0.56)$ \\
Enjoyment & 6.16 & 6.00 & 6.44 & 5.29 & 5.98 \\
& $(0.67)$ & $(0.69)$ & $(0.61)$ & $(0.43)$ & $(0.77)$ \\
\hline
\end{tabular}

* The table shows mean scores for the three value domains defined by the factoranalytic procedure separately for the five cooperation types. Standard deviations in parentheses.

\subsection{Value domains and cooperation preferences}

Table 4 reports mean scores and standard deviations for the three value domains defined by the factor-analytic procedure separately for the five cooperation types.

A one-way analysis of variance showed significant differences between the mean scores of the five cooperation types for the Prosocial $(F=2.98, p<0.05)$ and Enjoyment $(F=2.80, p<0.05)$ value domains, but not for the Maturity domain $(F=0.73, p=0.57)$. Visual inspection of the data revealed that only the Prosocial domain scores were positively associated with cooperation preferences. Fig. 2 illustrates this relationship.

$T$-tests showed that ConsistentFR had significantly lower mean scores on the Prosocial domain than 2timesCC $(p<0.05)$, ConsistentCC $(p<0.01)$ and All other $(p<0.05)$. We used MLR analysis to predict probabilities of the five cooperation types dependent on the Prosocial domain scores. Table 5 reports the results.

Parameters from Table 5 are again best interpreted in terms of odds ratios $(\operatorname{Exp}(\lambda))$. For example, an increase of the Prosocial domain score by one point made it 4.69 times more likely that a participant was categorized as ConsistentCC instead of ConsistentFR. The MLR-model reported in Table 5 had a Nagelkerke $R^{2}$ of 0.14 (Model Fit $\chi^{2}=9.79, p<0.05$ ).

\subsection{Big-Five personality dimensions, value domains $\mathcal{E}$ cooperation preferences}

In a last step of our analysis we investigated how personality (i.e., Agreeableness) and personal values (i.e., Prosocial values) jointly impact cooperation preferences. We first assessed the relationship between Agreeableness and the Prosocial value domain. Spearman rank correlation analysis showed that both variables were positively correlated $(\rho=0.43, p<0.01)$. When entered simultaneously in a MLR-model, only Agreeableness emerged as 


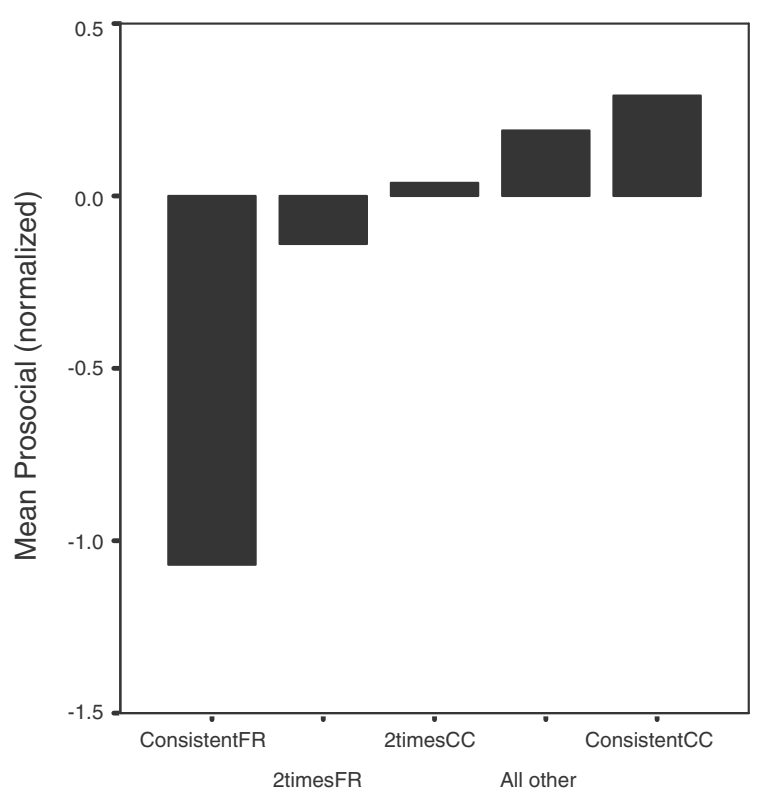

Fig. 2. The figure shows scores on the Prosocial value domain for the five cooperation types. To facilitate the interpretation we de-meaned and standardized the domain scores.

Table 5

Multinomial logistic regression analysis*.

\begin{tabular}{llrllll}
\hline $\begin{array}{l}\text { Dependent } \\
\text { variable: } \\
\text { Cooperation }\end{array}$ & $\begin{array}{l}\text { Independent } \\
\text { variable: } \\
\text { type }\end{array}$ & $\lambda$ & $\begin{array}{l}\text { Std. } \\
\text { error }\end{array}$ & Wald & $p_{\text {wald }}$ & $\operatorname{Exp}(\lambda)$ \\
\hline ConsistentCC & Intercept & -7.02 & 3.16 & 4.96 & 0.026 & \\
& Prosocial & 1.55 & 0.60 & 6.70 & 0.010 & 4.69 \\
All Other & Intercept & -6.42 & 3.26 & 3.88 & 0.049 & \\
& Prosocial & 1.37 & 0.62 & 4.95 & 0.026 & 3.94 \\
2timesCC & Intercept & -5.03 & 3.07 & 2.68 & 0.102 & \\
& Prosocial & 1.13 & 0.59 & 3.66 & 0.056 & 3.08 \\
2timesFR & Intercept & -4.78 & 3.81 & 1.57 & 0.210 & \\
& Prosocial & 0.87 & 0.72 & 1.46 & 0.226 & 2.39 \\
\hline
\end{tabular}

${ }^{*}$ The table shows parameter estimates $(\lambda)$ and odds ratios $(\operatorname{Exp}(\lambda))$ from MLR for four cooperation types. Reference category is ConsistentFR.

a significant predictor of cooperation types $\left(\chi^{2}=13.28, p<0.01\right)$, while the effect of the Prosocial domain became insignificant $\left(\chi^{2}=3.36, p=0.50\right)$. Hence, participants' scores on the Prosocial value domain did not uniquely contribute to the prediction of cooperation types when controlling for Agreeableness. The joint model had a Nagelkerke $R^{2}$ of 0.30 (Model Fit $\chi^{2}=23.07, p<0.01$ ).

\section{Discussion}

In the present study we examined how cooperation preferences in PGGs are related to personality traits and personal values. Our findings showed that the Big-Five personality dimension Agreeableness was a strong predictor of individual preferences for cooperation in a series of three PGGs conducted over the course of five months. Participants who scored low on Agreeableness were more likely to exhibit stable selfish preferences, while participants scoring high on Agreeableness were more likely to exhibit stable cooperative preferences. This finding on underlying cooperation preferences is in line with previous findings on displayed cooperation behavior, indicating that Agreeableness, which was defined by John and Srivastava (1999, p. 121) as "a prosocial and communal orientation towards others", is associated with cooperativeness in social dilemma situations (e.g., Pothos, Perry, Corr, Matthew, \& Busemeyer, in press). This result is not unexpected, given that social dilemmas face subjects with the choice between self-interests (free riding) and collective interests (cooperation) and individuals high on Agreeableness are more inclined to forgo self-interests in favor of collective interests than individuals low on Agreeableness (e.g., Buss, 1991; Graziano \& Eisenberg, 1997).

Our findings also showed that participants' scores on a Prosocial value domain derived from Rokeach's terminal values were indicative of their cooperation preferences in the PGGs. While value domains are generally fuzzy concepts (Schwartz, 1994, p. 25), the values included in our Prosocial domain were largely consistent with Feather's (1991) Universal prosocial domain (equality, a world of beauty, a world at peace, inner harmony and freedom). Participants who scored low on this domain were more likely to consistently exhibit selfish preferences than participants with high domain scores. Our results suggest therefore that weak prosocial values are related to preferences for free riding in PGGs.

Finally, we found that Agreeableness and the Prosocial value domain were moderately correlated. When both variables were simultaneously entered into a regression equation, the effect of the Prosocial domain dropped to non-significance, whereas Agreeableness remained significant. Both constructs apparently accounted for considerable overlapping variance in the prediction of cooperation preferences, with Agreeableness being the stronger predictor. Olver and Mooradian (2003) argued that while personality and values capture distinct characteristics of a person, they are also related and interdependent. In our study, interdependence outweighed distinctiveness as personal values did not uniquely contribute to the prediction of cooperation preferences above and beyond what was already accounted for by personality.

Taken together, the present study promotes our understanding of the relationship between individual difference variables and economic behavior by exploring dispositional determinants of cooperation preferences in PGGs. More specifically, it sheds light on the under-researched issue of how personality traits and personal values separately and jointly impact behavior. While some previous studies have also examined the impact of personality and/or values on cooperative choices in social dilemma situations (e.g., Lönnqvist, Walkowitz, Wichardt, Lindeman, \& Verkasalo, 2009; Sagiv, Sverdlik, \& Schwarz, in press), our study is the first to dig deeper and focus on cooperation preferences that reveal the underlying motives or reasons for competitive versus cooperative behavior. Furthermore, in contrast to previous research we aggregated behavioral observations from a series of three public goods games conducted over a time span of five months. Research has shown that relationships between personality traits and behavior are more likely to be detected if aggregate measures built from multiple observations of behavior are used, as those reduce measurement error and unreliability (see e.g., Epstein, 1979).

The study could be improved upon by employing a longer personality measure. For example, while Gosling et al. (2003, p. 523) pointed out that "very brief instruments can stand as reasonable proxies for longer Big-Five instruments" and Donnellan et al. (2006, p. 202) concluded that "it is possible to make very effective measures of broad constructs with relatively few items", any nonsignificant results obtained with a very brief instrument such as the TIPI should be interpreted tentatively. Furthermore, because the TIPI does not provide facet-level scores, we can only speculate that the Agreeableness facet compliance (as the opposite pole of aggressiveness and competitiveness) is most closely related to cooperation preferences in public goods games. Focusing less on the big picture and more on the effects of the different facet-level constructs of Agreeableness and other Big-Five dimensions on cooperation in social dilemma situations would therefore be a 
worthy area for future research. Furthermore, given our findings, we believe that future research should focus less on single predictors and more on the joint effects of individual difference variables to gain a more holistic understanding of the determinants of cooperative behavior in social dilemma situations.

\section{References}

Buss, D. M. (1991). Evolutionary personality psychology. Annual Review of Psychology, 42, 459-491.

Costa, P. T., \& McCrae, R. R. (1992). Revised NEO personality inventory (NEO PI-R) and NEO five-factor inventory (NEO FFI) professional manual. Odessa, FL: Psychological Assessment Resources.

Donnellan, M. B., Oswald, F. L., Baird, B. M., \& Lucas, R. E. (2006). The mini IPIP scales: Tiny yet effective measures of the Big Five factors of personality. Psychological Assessment, 18, 192-203.

Ehrhart, M. G., Ehrhart, K. H., Roesch, S. C. Chung-Herrera, B. G., Nadler, K, \& Bradshaw, K. (2009). Testing the latent factor structure and construct validity of the Ten-Item Personality Inventory. Personality and Individual Differences, 47, 900-905.

Epstein, S. (1979). The stability of behavior: On predicting most of the people much of the time. Journal of Personality and Social Psychology, 37, 1097-1126.

Feather, N. T. (1991). Human values, global self-esteem and belief in a just world. Journal of Personality, 59, 83-107.

Fischbacher, U. (2007). Z-Tree: Zurich toolbox for ready-made economic experiments. Experimental Economics, 10, 171-178.

Fischbacher, U., Gächter, S., \& Fehr, E. (2001). Are people conditionally cooperative? Evidence from a public goods experiment. Economic Letters, 71, 397-404.

Fleming, P., \& Zizzo, D.J. (in press). Social desirability, approval and public good contribution. Personality and Individual Differences. doi:10.1016/ j.paid.2010.05.028.

Furnham, A. (2008). Relationship among four Big Five measures of different length. Psychological Reports, 102, 312-316.

Goldberg, L. R. (1999). A broad-bandwidth, public domain, personality inventory measuring the lower-level facets of several five-factor models. In I. Mervielde, I Deary, F. De Fruyt, \& F. Ostendorf (Eds.), Personality psychology in Europe (pp. 7-28). Tilburg: Tilburg University Press. Vol. 7
Gosling, S. D., Rentfrow, P. J., \& Swann, W. B. (2003). A very brief measure of the Big-Five personality domains. Journal of Research in Personality, 37. 504-528.

Graziano, W. G., \& Eisenberg, N. H. (1997). Agreeableness: A dimension of personality. In R. Hogan, J. Johnson, \& S. Briggs (Eds.), Handbook of personality psychology (pp. 795-824). London: Academic Press.

Herrmann, B., \& Thöni, C. (2009). Measuring conditional cooperation: A replication study in Russia. Experimental Economics, 12, 87-92.

Hirsh, J. B., \& Peterson, J. B. (2009). Extraversion, neuroticism, and the prisoner's dilemma. Personality and Individual Differences, 46, 254-256.

John, O. P., \& Srivastava, S. (1999). The Big Five trait taxonomy: History, measurement, and theoretical perspectives. In L. A. Pervin \& O. P. John (Eds.) Handbook of personality: Theory and research (pp. 102-138). New York: Guilford Press.

Kelley, H. H., \& Stahelski, A. J. (1970). Social interaction basis of cooperators' and competitors' beliefs about others. Journal of Personality and Social Psychology, 16 66-91.

Kramer, R. M., McClintock, C. G., \& Messick, D. M. (1986). Social values and cooperative response to a simulated resource conservation crisis. Journal of Personality, 54, 576-591.

Lönnqvist, J. E., Walkowitz, G., Wichardt, P., Lindeman, M., \& Verkasalo, M. (2009). The moderating effect of conformism values on the relations between other personal values, social norms, moral obligation, and single altruistic behaviours. British Journal of Social Psychology, 48, 525-546.

Olver, J. M., \& Mooradian, T. A. (2003). Personality traits and personal values: A conceptual and empirical integration. Personality and Individual Differences, 35, $109-125$.

Parks, L., \& Guay, R. P. (2009). Personality, values, and motivation. Personality and Individual Differences, 47, 675-684.

Pothos, E. M., Perry, G., Corr, P. J., Matthew, M. R., \& Busemeyer, J. R. (in press). Understanding cooperation in the Prisoner's Dilemma game. Personality and Individual Differences. doi:10.1016/j.paid.2010.05.002.

Rokeach, M. (1973). The nature of human values. New York: Free Press.

Sagiv, L., Sverdlik, N., \& Schwarz, N. (in press). To compete or to cooperate? Values' impact on perception and action in social dilemma games. European Journal of Social Psychology. doi:10.1002/ejsp.729.

Schwartz, S. H. (1994). Are there universal aspects in the structure and contents of human values? Journal of Social Issues, 50, 19-45

Schwartz, S. H., \& Bilsky, W. (1990). Theory of the universal content and structure of values: Extensions and cross-cultural replications. Journal of Personality and Social Psychology, 58, 878-891. 